Lexis Vol. XLV (2) 2021: 765-795

\title{
Figura y traición en el Libro de Alexandre
}

\author{
Arturo Ruiz Mautino \\ https://orcid.org/0000-0003-2745-7361 \\ Cornell University \\ ar2358@cornell.edu
}

\begin{abstract}
RESUMEN
El artículo explora la posibilidad y condiciones de una interpretación figural del Libro de Alexandre. Propone, en consonancia con lecturas recientes de la obra maestra del mester de clerecía, que la traición, en tanto evento iterativo y núcleo moral en el poema, configura un punto de acceso idóneo para la comprensión de la estructura del texto y de su autoconciencia poética. Se provee un esquema matricial para la evaluación de las diversas instancias de traición en el texto y se vislumbra un modo para considerar su vigencia en la producción literaria contemporánea en lengua española.
\end{abstract}

Palabras clave: Libro de Alexandre, mester de clerecía, figura, traición

Figura and Betrayal in the Libro de Alexandre

\section{Abstract}

The article explores the possibility and conditions of a figural interpretation of the Libro de Alexandre. It proposes, in line with recent takes on the mester de clerecía masterpiece, that treason, as an iterative event and as a moral nucleus of the poem, configures an ideal entry point for apprehending the structure of the text and its poetic self-awareness. We provide 
a matrix for the scrutiny of the diverse instances of betrayal in the text and we envision a way to assess its validity in contemporary literature written in Spanish.

Keywords: Libro de Alexandre, mester de clerecía, figura, betrayal

\section{INTRODUCCIÓN A UN PROBLEMA CATEGORIAL}

Resulta tentador pensar que solo de la inseguridad puede brotar una historia de ella misma como dispositivo retórico en escrituras relativamente contemporáneas.

En el universo hispánico, favorece a tal empresa el precedente luminoso del "Prólogo" dirigido al desocupado lector con que Cervantes da comienzo a la Primera parte del Quijote de 1605. Allí, un género célebre de inseguridad post festum por parte del padrastro de don Quijote promueve que aquel “amigo mío, gracioso y bien entendido” (Cervantes 1997: 7) resuelva, a un tiempo, la futilidad de pretender erudición y la necesidad de dar por acabada tal escaramuza en el menor tiempo posible y con el menor gasto de energía. Concurre en el prólogo, junto al encanto de la falsa modestia amplificada y transformada en diálogo de amigos, el despliegue retórico de una inseguridad que convoca la fantasía de la familia intertextual, siendo que, como se recordará, "El remedio que esto tiene es muy fácil, porque no habéis de hacer otra cosa que buscar un libro que los acote todos, desde la A hasta la z, como vos decís. Pues ese mismo abecedario pondréis vos en vuestro libro" (11). Uno podría preguntarse por la forma de dicha convocatoria: si obedece a la lógica del síntoma, encontrando que incluso la performance de la inseguridad necesita figurarse un apoyo desde donde erigir su palabra; si obedece, más bien, a una vieja concatenación naturalizada por el estudio y gozo de las artes retóricas; o si, por último, es todo vana y originalísima literatura, lo que equivale a no decir nada.

Invoco tal precedente con la sospecha de que vale la pena examinar las maneras en que el discurso crítico hispanista se revela a 
sí mismo sensible al influjo retorizante de sus clásicos, con la inseguridad, la vacilación o el titubeo autorial en medio de la escena. En la galaxia del metatexto, constelaciones que renuevan la impresión de que detrás de lo canónico, de lo que ha venido a establecerse como clásico, en suma, se halla algo más que la mera institucionalidad o los meros hábitos de lectura. El caso que examino lo constituye el Libro de Alexandre, largo poema épico de disputada autoría (allí, una primera vacilación, superada la certidumbre con que Dana Arthur Nelson atribuyó el poema a Gonzalo de Berceo) que, desde sus estrofas iniciales, facilitó a la historia del español el ubicarlo en la esfera del llamado mester de clerecía de principios del siglo XIII. Los casi 2675 tetrástrofos monorrimos que lidian con el ascenso y caída de Alejandro el Grande, que medievalizan la vida del emperador macedonio a partir de la negociación con los discursos y axiomas de la tradición escolástica, han propiciado una considerable literatura crítica que pone de manifiesto el desafío, tan ineludible como productivo, de la unidad en la variedad. El Libro de Alexandre, espejo en sí mismo del apetito intelectual que caracteriza a su héroe, aglutina una gama extensa de saberes (desde lo histórico-legendario hasta la filosofía natural) según el uso de figuras de amplificación. De aquel exceso, a un tiempo intertextual y didáctico, emerge un problema de responsabilidad exegética, para la que resulta crucial la pregunta por el detalle y por todo aquello que, en apariencia, deviene secundario para la aprehensión del destino del héroe del poema y de su ejemplar trayectoria protofáustica.

Ante esta segunda vacilación, que remite a la regularidad de una forma - la cuaderna vía - para la que no existe detalle digresivo tan secundario que merezca el abandono del monorrimo, han sido pensadas soluciones varias. Connatural a los usos críticos de los tiempos de la vieja diosa (Rubio Tovar 2004), la exhaustividad filológica se muestra como una alternativa natural. He allí, por ejemplo, The Treatment of Classical Material in the Libro de Alexandre, donde Ian Michael examina aspectos de medievalización, cristianización y moralización a partir del terreno seguro del diálogo con las fuentes, entre las que destaca, como es común desde los trabajos 
de Raymond S. Willis, el Alexandreis de Gautier de Châtillon. Ya en 1970, antes de arrostrar las transformaciones impresas por el poema al material que constituye su red de hipotextos, Ian Michael se vio en la necesidad de justificarse ante su corpus. Juzgó pertinente defender no ya un método ni un programa de indagación, sino el mero afán de dedicar algo de tiempo y de estudiosa soledad a un poema para el que el tópico de la desmesura reclama desmesura digresiva sin par. El comentarista actual del Libro de Alexandre solo puede agradecer que el paso de casi cincuenta años desde la publicación de The Treatment... haya vuelto innecesario sostener que "The vernacular poem's complexity of structure is sufficient reason for making it the object of a critical study" (Michael 1970: 4). Sus problemas son de otra índole, como lo son las razones de su angustia. Sitiado por una bibliografía de dimensiones tal vez engañosas, ha de conjurar toda pretensión de novedad con la humildad de quien ha retenido cuando menos los avisos contra la soberbia, la cobdiçia y las malas interpretaciones que saturan los versos de aquel anónimo clérigo autor del Alexandre, consciente, como argumentó Willis, de su maestría y del ministerio que esta le suponía (213-214).

Recordaba más arriba cómo es que la ansiedad citacional se resolvía en el prólogo de la Primera parte del Quijote con arreglo a lo que llamé la fantasía de la familia intertextual. El "gracioso y bien entendido" amigo del prologuista da con el remedio del simulacro, en tanto que la erudición pasa a ser máscara de quien se limita a transcribir los frutos de la lectura de otros. No obstante, como atestiguan las comunidades de copistas detrás de textos como el Alexandre, incluso en la tarea de la copia hay un elemento de selección que hace que el consejo de aquel "gracioso y bien entendido" amigo revista mayor buena fe de la que inicialmente se le puede reconocer. Una buena fe análoga me lleva, enfrentado al referido problema de la unidad en la variedad, a buscar el amparo de una familia de textos para la que lo heterogéneo en el Libro de Alexandre ha de decodificarse según un plan de relaciones intra y extratextuales que problematizan la vieja frontera entre poesía e historia. 
Me refiero al conjunto de textos que, desde hace no muchas décadas, han considerado con alguna seriedad la posibilidad de leer el Alexandre conforme al esquema de la figura. Como ellos, propongo aquí una clave de lectura que busca reunir los elementos más marcadamente digresivos del poema en una estructura de correspondencias que no debió de ser ajena a los esquemas de interpretación medieval. La lectura figural — pariente en nuestra imaginación postraslaticia de la alegoría y la anagoge- señala un tipo de relacionalidad en la que devienen fundamentales ideas de complementariedad y prefiguración. La iniciativa en sí de aplicarla (o, más precisamente, buscarla) en el Alexandre no es novedosa. En el ya citado estudio de Ian Michael, el estudioso británico prevé la posibilidad de una lectura figural del Alexandre y la descarta, aduciendo que sus posibles significados tipológicos no quedan satisfactoriamente indicados en el poema: ni la dupla de tipos patrísticos Jerusalén-Babilonia — virtualmente aludida por la visita de Alejandro a aquella y su entrada triunfal a esta- ni el significado dudosamente tipológico de los animales que el rey encuentra en sus campañas - entre los que destacan los elefantes y las serpientes - reúnen suficiente evidencia textual. Tal consideración corresponde a una aplicación de la estructura figural inspirada por sus raíces hermenéuticas religiosas, en la medida que "The text of the Alexandre does not support any religious typology, but in a recent lecture A. D. Deyermond has put forward the suggestion of secular or quasi-typology in the poem, which it would be interesting to see elaborated, though this might not always be easy to distinguish from mere simile or comparison" (9-10).

Tal es el primer miembro de la familia de textos a la que apelo: primer miembro donde la posibilidad de lo figural en el Alexandre se inaugura en su negación. Dos años después de la publicación de The Treatment..., Peter Bly y Alan Deyermond, a quien aludió Michael, publicaron "The Use of Figura in the Libro de Alexandre". Bly y Deyermond acometen la tarea de iluminar las abundantes digresiones del poema, privilegiando la larga digresión troyana que el poeta pone en boca de Alejandro entre las estrofas 
334 y $761^{1}$, con la tesis de que tales segmentos del texto configuran un sustrato figural para la correcta interpretación de la caída del rey macedonio (Bly y Deyermond 1972: 153). Se advertirá que Bly y Deyermond se aproximan al Alexandre de la mano de un ideal de contemporaneidad que los emparenta con aquel virtual historiador de la literatura que, según Vodička, ha de interesarse por las normas literarias de una era, por sus patrones de recepción y su particular sensibilidad, antes que por los significados ocultos que una arqueología exegética pudiera exhumar (Vodička 1989: 55). Bly y Deyermond lo tuvieron en cuenta al argüir que la interpretación figural cuenta con la ventaja de que era accesible incluso a aquellos fruidores del Alexandre no particularmente educados, "whereas the more complex and abstruse method of exegesis known as allegoria was comprehensible only to a small group of specialists" (Bly y Deyermond 159).

Diez años después de que Bly y Deyermond revirtieron el dictamen de Michael contra la figura en el Alexandre, Michael R. Solomon y Juan Carlos Temprano publicaron el ensayo "Modos de percepción histórica en el Libro de Alexandre”, el cual, en desmedro de los reparos de Michael, acierta al extender las resonancias figurales del poema hacia realidades extratextuales relevantes para el fruidor contemporáneo del Alexandre. Solomon y Temprano encuentran que los hallazgos en materia de estructura figural de Bly y Deyermond son insuficientes. No basta con afirmar que Paris, Aquiles, Darío, los elefantes de Poro - mediatizados por el Physiologus - y el propio Lucifer son figuras de Alejandro (Bly y Deyermond 159-173). Se apoyan en algunos rasgos específicos del Alexandre español (la exaltación del honor y de su educación y cultura, por ejemplo) para establecer que el rey macedonio, tal como aparece en el poema, es figura de Fernando III el Santo: las semejanzas entre los dos reyes son suficientes para concluir que el

1 Empleo, para el citado del poema y la indicación rápida de sus estrofas numeradas, la edición del Libro de Alexandre de Juan Casas Rigall del 2014. 
monarca español perfecciona a Alejandro en tanto acontecimiento histórico (Solomon y Temprano 1982: 14-17)2.

La exhaustividad está en disputa en esta pequeña familia de textos. En consonancia con el imperativo barthesiano de "transformarlo todo" (Barthes 1972: 67) mediante la anamorfosis razonada de la crítica, el mecanismo figural aspira a localizar agentes y eventos en el poema (y fuera de él) que se comprometan en binomios de complementariedad y en un régimen temporal donde lo presente contiene lo futuro. Argumentaré que es posible extender las propuestas de Bly y Deyermond y de Solomon y Temprano más allá del eje inmediato de Alejandro. Vuelvo a los planteamientos de Erich Auerbach en su ensayo sobre la Figura para aprovechar algunas implicaciones estructurales de la vieja categoría. Buscaré también corroborar que el uso de la figura en el Libro de Alexandre anticipa un modo más bien actual de abordar problemas de economía de la trama, particularmente en el campo de la novela maximalista. Confío en que algo de la intemporalidad inherente a un concepto patrístico de figura facilite esta extrapolación.

\section{EN TORNO A LA FIGURA}

Puesto que he anunciado que la impugnación a un cierto modo de detectar lo figural en el Libro de Alexandre constituye la base de mi análisis, dedico algunas líneas a la clarificación de lo que he de entender como figura. Quiero enfatizar las peculiaridades interpretativas que se derivan del uso de la categoría, tal como la presenta

2 Solomon y Temprano tienen en cuenta, como semejanzas entre Fernando III y Alejandro Magno, el proyecto de la reconquista, el privilegiado estatuto axiológico del honor, y la "educación y cultura" destacables en ambos reyes. Una semejanza considerablemente más notable ha sido señalada por Juan Manuel Cacho Blecua, quien observa que tanto Alejandro como Fernando III se invistieron armas a sí mismos: "La investidura de armas suponía unas relaciones y dependencias entre los participantes de la ceremonia, y la existencia de alguien superior que la otorgaba. Al eliminar a este intermediario, fuera laico o eclesiástico, se suprimían las posibles relaciones y se afirmaba el carácter autónomo, independiente, de la realeza" (1994: 202). La tonalidad moral del Alexandre hará que la autonomía y la independencia mencionadas por Cacho Blecua adquieran visos de desmesura individualista. 
Erich Auerbach en su ensayo citado, en particular porque intuyo que un manejo laxo del concepto ha decidido, por un lado, que se restrinja su empleo a la cadena que ubica al personaje de Alejandro como veritas o como umbra (1998: 75), y, por el otro, que siga siendo parcialmente válida la objeción de Ian Michael sobre la pertinencia de usarlo cuando basta señalar un símil (1970: 10). Tras explicar las transformaciones semánticas de la palabra 'figura' desde su uso por autores como Lucrecio, Varrón y Cicerón hasta su adquisición de significado técnico en la retórica de Quintiliano y el discurso arquitectónico de Vitruvio, Auerbach explica que el primer uso interpretativo de la figura correspondió a la decodificación eclesiástica de las Sagradas Escrituras (1998: 67-70). Con el afán de conciliar el Antiguo y el Nuevo Testamento, padres de la Iglesia como Tertuliano y Orígenes emprendieron la instrumentalización de la figura como "ese algo verdadero e histórico que representa y anuncia otro algo igualmente verdadero e histórico”, de manera que la "relación de reciprocidad entre ambos acontecimientos se deja reconocer por su coincidencia o semejanza” (69). Se encuadró, por ejemplo, a Adán como figura Christi y a Eva, como figura Ecclesiae, con la ventaja pragmática para la Iglesia de que la figura, a diferencia de la alegoría, mantenía un grado considerable de sujeción a lo real e histórico. Esto, en manos de San Pablo, permitió convertir el Antiguo en profecía real del Nuevo Testamento. De ese modo, en el marco de proyectos misioneros, no había necesidad de descartar el Antiguo Testamento, haciéndolo más admisible en comunidades que no fuesen judías (97-98). La secularización de la figura, mantiene Auerbach, implicó su penetración en ámbitos muy particulares de la producción literaria de la Edad Media, entre los que destaca el drama religioso (109). Para ese punto, no obstante, su estabilización como herramienta exegética había supuesto optar por algunos caminos teóricos en detrimento de otros. En la historia de tales elecciones, destaca la oposición entre un realismo de lo figural, representado por el sensorialismo de Tertuliano y su adhesión a la historicidad de la figura (70-71), y la inclinación a lo alegórico y abstracto, representada por el espiritualismo de Orígenes (77). 
En Occidente, observa el crítico alemán, hubo de imponerse la primera de las dos vías (78-79).

Esta divergencia en la aprehensión de lo figural ha resultado decisiva en la manera como se ha pretendido leer tipológicamente al rey macedonio en el Libro de Alexandre. Tanto Bly y Deyermond como Solomon y Temprano han optado por limitar el número de acontecimientos susceptibles de encadenarse en cadenas figurales en el Alexandre. Para Bly y Deyermond, la tipología secular del Libro de Alexandre genera un patrón que explica la caída de Alejandro y que conjuga de forma satisfactoria sus tres factores preponderantes, es decir, "Alexander's cobdiçia, the sudden reversal of fortune, and the workings of treason" (1972: 181). Con ello, se resuelve el problema de la larga digresión troyana y se explica la lógica especular de una secuencia de acontecimientos, pero no mucho más. No menos timorata resulta la tesis de Solomon y Temprano, en la medida que, para corroborar que el Alejandro cristianizado ha sido modelado según las virtudes de un virtual rey hispano, basta con detenerse en la comparación del Alexandre con las fuentes consultadas por su autor anónimo.

No es, sin embargo, la relativa sofisticación de las hipótesis de Bly, Deyermond, Solomon y Temprano lo que objeto, sino que no se haya aprovechado la noción de figura para otra cosa que el comentario de un subconjunto reducido de las dimensiones problemáticas del poema. Queda por indagar, por ejemplo, si el uso de la figura explica algo de la conciencia que tenía el autor del Alexandre acerca de su ministerio, es decir, de su mester, y si los caminos que abre esa pregunta pueden favorecerse de un entendimiento de lo figural que se aparte de lo estrictamente histórico o mimético.

Desde un punto de vista metodológico, esta última cuestión no es baladí. Tomar al pie de la letra las definiciones complementarias de figura, escamoteando la tendencia decisoriamente occidental de interpretar los miembros de la articulación figural como reales eventos históricos, no proporciona ninguna solución unívoca. La formulación básica es la siguiente: "La interpretación figural establece entre dos hechos o dos personas una conexión en la que uno de ellos no se reduce a ser él mismo, sino que además equivale al 
otro, mientras que el otro incluye al uno y lo consuma" (Auerbach 1998: 99)33 de manera que:

a) Ambos hechos o personas están "temporalmente separados"

b) a diferencia de la alegoría, la interpretación figural lidia "con la historicidad real tanto de la cosa significante como de la cosa significada" (100);

c) los dos hechos o personas "se refieren mutuamente el uno al otro y señalan hacia un futuro inminente que será el acontecimiento pleno real y definitivo" (106), acontecimiento que determina una promesa en una "configuración provisional de lo eterno, recurrente e intemporal” (108).

Trasladada la interpretación de la figura al mundo ficcional del Libro de Alexandre, se ha establecido con cierto automatismo que los miembros de la cadena figural han de ser personajes o, al menos, sujetos individuales de realidad textual o extratextual: los elefantes de Poro, por ejemplo, pero también Fernando III. Desactivar ese automatismo no es del todo sencillo pues intervienen en el asunto tres cuestiones. La primera concierne al estatuto de lo figuralmimético en la lectura del Alexandre y la posibilidad de preferir lo figural-alegórico o figural-abstracto de acuerdo con la versión de figura preconizada por Orígenes. Esto supone confiarse a una teoría de la ficción que explique la traslación del contenido histórico de la interpretación figural patrística al ámbito de la literatura, problema que se suma al hecho de que la historia del rey macedonio se ubica en el terreno difuso de lo legendario ${ }^{4}$. La segunda tiene que ver con cómo imaginar el papel del crítico que emplea la estructura

\footnotetext{
El primer miembro del binomio, aquel que anuncia al otro, recibe el nombre de figura, umbra o imago. El segundo miembro es la 'consumación' del primero, también llamada veritas (Auerbach 1998: 75).

4 Este aspecto del problema suscita consecuencias interesantes, de lo cual es sintomático un caso reciente. La localización de la historia de Alejandro en lo legendario ha motivado que Fernando Riva (2018) documente el enlace entre la dimensión moral y la dimensión monárquica del poema basándose en una genealogía de reyes babilónicos atravesada por la soberbia (Nabucodonosor, Baltasar, Nemrod), la cual, como la historia de Alejandro, tiene bases textuales indisociables de lo legendario.
} 
figural para iluminar el Alexandre: si ha de pensarse en tanto historiador de la literatura, en el sentido arriba citado de Vodička, o si ha de admitirse que la lectura figural implica per se una voluntad interpretativa que, en concordancia con una de las acepciones metafóricas de la palabra 'figura' —activa, según Auerbach, tanto en la obra de Aristóteles y San Agustín como en la de San Isidoro (1998: 48-49)— ${ }^{5}$, imprime su sello en el cuerpo del texto. La tercera, finalmente, corresponde a la legitimidad de establecer conexiones figurales entre elementos del poema y realidades extratextuales ${ }^{6}$.

Si bien, en tanto gesto crítico que busca atenuar la especificidad histórica del Libro de Alexandre, la asunción de una lectura figural independiente de intenciones autoriales resulta atractiva, optar por ella acarrea al menos la precaución de no multiplicar inútilmente los eslabones figurales posibles. De ese modo, habiendo resuelto la segunda de las tres interrogantes arriba planteadas, la tercera aparece imposible de resolverse a priori: ciertas configuraciones figurales demandarán cuando menos la promesa de un acontecimiento futuro de naturaleza rigurosamente extratextual, como lo es el Juicio Final según la interpretación patrística de la Encarnación. De hecho, tengo que el Libro de Alexandre constituye, al respecto, un caso excepcional. No será necesario inquirir demasiado más allá del texto en sí para hallar una instancia de enjundiosa consumación figural, relativa al viejo asunto del género al que pertenece.

5 Explorando los sentidos de 'figura' en su evolución del griego al latín, asegura Auerbach que "En efecto, no se perdió totalmente el significado de «lo plástico», puesto que

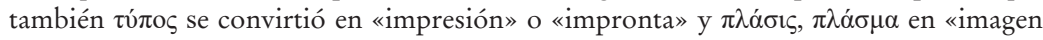
plástica», como resultaba de la raíz fig-, que frecuentemente se convierte en figura. A

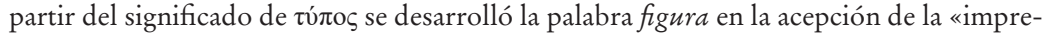
sión de un sello» [...]” (48).

${ }^{6}$ La tesis citada de Solomon y Temprano (Alejandro como figura de Fernando III) se inserta en un vasto arreglo de lecturas que implican una dimensión de lo monárquico real, lo monárquico hispánico, en la interpretación del Alexandre. Es posible que la más tradicional corresponda a imaginar el poema como un speculum principis diseñado con un tipo específico de personalidad regia en mente. Naturalmente, la lógica del speculum principis reclama un circuito de lectura, una audiencia, en suma, que exceda al de los virtuales clérigos-escolares colegas del autor del Alexandre. Para una exploración pormernorizada de la prefigurada recepción del Alexandre en la órbita de lo cortesano y lo monárquico caballeresco, véase Arizaleta 2000. 


\section{Eslabones DE LA TRAICIÓN: UN SIMULACRO DE TIPOLOGÍA}

Suponiendo que es posible darse por satisfecho desechando la dimensión ontológica de la primera de las tres interrogantes formuladas arriba, persiste la pregunta sobre qué forma ha de tener una lectura figural del Alexandre que dé por descontadas secuencias de acontecimientos o personas de iluminación recíproca, según el modelo de la "profecía real". Podría pretenderse la conquista de un balance entre las dos vertientes de la figura, semejante al que, de acuerdo con Auerbach, logró la obra agustiniana (1998: 79). No obstante, incluso así, la traslación de lo figural-alegórico o figuralabstracto al mundo del Alexandre requiere una toma de decisión respecto a cómo renunciar a la dependencia de lo literal. Por fortuna, aquí el texto mismo provee una indicación sobre qué camino seguir, al menos según ha propuesto Michael Agnew con relación a los actos de fallida interpretación en el poema. Agnew arguye que el conjunto de malas lecturas desplegadas por los protagonistas del Alexandre conduce a la idea de que "las lecturas espiritualmente defectuosas siempre deben rectificarse; si no, la verdadera sabiduría permanecerá fuera del alcance del lector” (Agnew 2000: 167). El máximo ejemplo de tal lectura defectuosa es Alejandro, incapaz, por ejemplo, a pesar del saber adquirido bajo la tutela de Aristóteles, de aprehender el memento mori en el epitafio de Aquiles (170), captando el sensus literalis de lo leído, mas no el sensus spiritualis (166). Agnew encuentra además que "el texto construye su propio modelo exegético” (180) mediante la profusión de instancias de interpretación insuficiente. En ese sentido, el Alexandre aspira a un didactismo negativo, basado en la multiplicación de ejemplos de cómo no han de leerse las cosas y estados de cosas en el mundo. ¿Cómo luce el reverso de la moneda? ¿Qué lección positiva sobre el lugar de lo alegórico o anagógico en la captura de significados que se escurren entre los dedos de Alejandro, Darío y otros tantos "lectores paganos" (181)?

Los caminos del didactismo en el Libro de Alexandre no son ilimitados. Se ha señalado muchas veces que la sanción contra 
la soberbia constituye el núcleo moral del poema, y ciertamente no hace falta cavar demasiado hondo para dar con ello, siendo que el poeta, en la descripción del infierno y de sus habitantes alegóricos - por citar uno de los pasajes más notorios-, sitúa a la soberbia como reina de los pecados capitales:

E todos estos tiene la Sobervia ligados:

todos son sos ministros, que traen sus mandados.

Ella es la reína, ellos son sus crïados:

a todos siet' los tien', ricament' doctrinados. (Alexandre 2406)

Junto con la soberbia, y si tenemos en cuenta solo las elocuciones explícitas de la voz poética, el didactismo del Libro de Alexandre remite a la traición y el menosprecio del mundo. El tópico del contemptus mundi es ubicuo. Refiero algunos momentos ejemplares. Después de que la Traición personificada concierta con Belzebub el modo de acabar con Alejandro, después de que el poema sintetiza las conquistas del rey macedonio y sus últimos proyectos de anexión imperial, leemos que:

Bien dixo el Salmista que lo que omne asma Asma omne grant salto quando cata, non puede en esto grant verdat:

todo es vanidat.

entre su voluntat:

salir a la meitdat. (2464)

Mucho antes, tras la muerte de Darío, víctima de la traición de Bessus y Narbozones ${ }^{7}$, el poeta dedica doce estrofas a la formulación lírica de la vanitas vanitatum, demostrando su pericia en la expolitio y en el uso de los eventos de su propia historia para la ejemplificación de sus lecciones, como se advierte en:

\footnotetext{
Para estos nombres propios, como para casi todos, sigo las lecciones preferidas por la edición de Juan Casas Rigall. Hago algunas excepciones con aquellos nombres que ya poseen una lección española establecida en el estado actual de la lengua, como 'Darío'.
} 
Dario, tan alto rëy, en cabo abés ovo no'l valió su imperio ¡quien en este mundo fía, omne de tan grant conta, una foya angosta; quanto una lagosta: él mismo se denosta! (1812)

Como tercer ejemplo, cito dos estrofas que el poeta coloca hacia el final del poema - tras dar gracias a Dios por haberle permitido dar por terminada la historia del rey macedonio-, definidas por la iteración de un deber condicional al ansia indudable de salvación:

Señores, quien quisier'

deve en esti sieglo

deve a Dios servir,

que en poder del mundo

La gloria d'esti mundo, más que la flor del campo ca, quando omne cuida échalo de cabeça su alma bien salvar assaz poco fïar: dévelo bien pregar non lo quiera dexar.

quien bien quisier'asmar non la deve preçiar, más seguro estar, en el peor lugar: (2670-2671)

He escogido tres instancias de amonestación explícita contra los proyectos mundanos para mostrar que, a pesar de lo diferentes que son sus pretextos diegéticos (el repaso de las conquistas de Alejandro, la muerte de Darío, el cierre de la historia), la conclusión didácticomoral es la misma. Entiendo que, con esa persistencia de lo mismo en lo variable, se haya llegado a argumentar que el Libro de Alexandre está estructurado como una secuencia de episodios de textura fundamentalmente moralista según el molde sentencia-ejemplo o ejemplo-sentencia (Cañas 1995: 72-75). No es del todo descabellado entrever una suerte de superestructura ejemplar en el poema basándose en la continuidad axiológica del contemptus mundi.

Hago eco aquí, sin embargo, de lecturas como la de Amaia Arizaleta, para quien, si bien hubo clérigos cultos entre el público lector del Alexandre para quienes el tópico del contemptus mundi hubo de resonar especialmente, "no deberíamos reducir el sentido 
del poema al estrictamente moralizante" (Arizaleta 2000: 5). Arizaleta encuentra natural que el carácter enciclopédico del poema y las condiciones de su recepción, particularmente complicadas por la extensión del texto, atrajeran públicos disímiles (6). Esto explica la discontinuidad de la materia moralizante, de particular relevancia en la valoración de la soberbia.

Con la soberbia, en efecto, el horizonte didáctico se complica. El poema es profuso en instancias donde se pasa de la exaltación a la condena del impulso (re)conquistador de Alejandro y viceversa. No intervienen en tal dinámica pendular solo los comentarios y ejercicios de erudición de la voz poética ${ }^{8}$, sino también las interacciones con los hombres del rey macedonio, la transformación de sus proyectos (de la ambición guerrera a la ambición epistemológica), y, por último, la intervención de Dios y Natura.

Los múltiples casos de traición en el poema apuntan a una heterogeneidad moral que tampoco puede reducirse a la llana condena. Es allí, en la constatación de una ambivalencia que puede incluso tomarse como correlativa, entre otras cosas, a una ansiedad de etiología económica (Pinet 2006: 61), donde la traición aparece como ámbito propicio para la inquisición de lo figural no-mimético o no-histórico en el Alexandre. Según argumento, una interpretación figural del Alexandre que interroga la valoración moral de la traición problematiza una vez más el horizonte de recepción del poema. En paralelo a la ampliación del circuito de lectura del texto, llevada a feliz término por críticos como la citada Amaia Arizaleta, identifico una forma de tensionar la relación entre el poema y un deseado lector para quien, participante del mester clerical, la traición adquiere relieves poetológicos.

Hacia el final de la parte teóricamente propositiva de su ensayo sobre la figura, Auerbach confiesa que no tiene "muy claro hasta

\footnotetext{
8 La propia Arizaleta observa que "No parece del todo justificado opinar que Alejandro es castigado por mostrar excesiva curiosidad intelectual, ya que su deseo de «meter en escripto los secretos del mar» se ve realizado, y de manera aparentemente ortodoxa, por el propio poeta anónimo" (Arizaleta 2000: 8), con lo que se ratifica que la tendencia a la digresión erudita del poeta refleja la desmesura epistémica del héroe.
} 
qué punto se pueden determinar figuralmente las ideas estéticas” (1998: 112). De vuelta al Alexandre y con la incertidumbre del crítico alemán en mente, me pregunto en qué medida puede determinarse figuralmente el contenido moral de cada episodio de traición. Con relación a la estructura de didactismo vislumbrada por Cañas, la articulación figural de lo moral tiene la ventaja de que desborda la mera yuxtaposición de lo semejante. Supone la existencia de un orden complementario a lo literal-histórico o literal-diegético, orden que no cancela la tensión de lo figural prospectivo, es decir, aquella arista de la figura que llevó a Solomon y Temprano a sostener que el componente deseado por la estructura del texto corresponde a la personalidad de Fernando III. La nueva tarea estriba en definir de qué moral type deviene token cada episodio relevante.

Como aquel vacilar al que me referí al inicio del ensayo, la premisa de que la traición es necesaria para el cumplimiento de un plan mayor cuenta también con un precedente insigne en español. En “Tres versiones de Judas”, que Borges fecha hacia 1944, el narrador que recorre los argumentos teológicos de la obra del sueco Nils Runeberg (desde el planteamiento de que el sacrificio de Judas Iscariote lo convierte en espejo de Cristo hasta la certidumbre de que Judas es el Mesías, pasando por la exaltación de su ascetismo, ilimitado por espiritual) afirma que "la traición de Judas no fue casual; fue un hecho prefijado que tiene su lugar misterioso en la economía de la redención” (Borges 1984: 515). En el Alexandre, la tesis de que la traición existe como engranaje necesario de la máquina que eleva y hace caer a Alejandro raya con lo trivial y, sin embargo, es útil, siempre y cuando se inquiera por qué y para quién la economía de la condena del rey macedonio ha de persistir como potencial salvoconducto hacia la redención. Hacia esa meta, intentaré mostrar que la traición no recibe un tratamiento moral unívoco en el poema, y que de ello depende la hipótesis de lo figural.

Bly y Deyermond han observado que "Treachery seems to obsess the poet; he sees it spreading its contagion everywhere, and he rails bitterly against its ministers" (1972: 162). Los casos a los que recurren los críticos ingleses para respaldar tal afirmación 
(la traición de Pausona contra Filipo, la de Narbozones y Bessus contra Darío, la de Judas contra Cristo —invocada como paralela a la traición de Bessus-, la de Antípater y Jobas contra Alejandro) se parecen en la medida que convocan la condena inmediata de la voz poética, no pocas veces con un furor anafórico digno de recuerdo. Tal es el caso después de la muerte del macedonio:

¡Maldito sea cuerpo que tal cosa faze!

¡Maldita sea alma que en tal cuerpo yaze!

¡Maldito sea cuerpo que d'aquello le plaze!:

¡Dios lo eche en lazo que nunca se deslaze! (Alexandre 2618)

Es claro, por otro lado, que la traición condenada no es siempre aquella a cuya morosa realización acuden los lectores del Alexandre. Más aun, no son pocas las ocasiones en que la traición se perfila como posibilidad apenas incoada, y más de una vez se exime a su ejecutor de toda culpa. Categorizo, en el cuadro siguiente, los casos que he encontrado en el texto: 
782 Lexis Vol. XLV (2) 2021

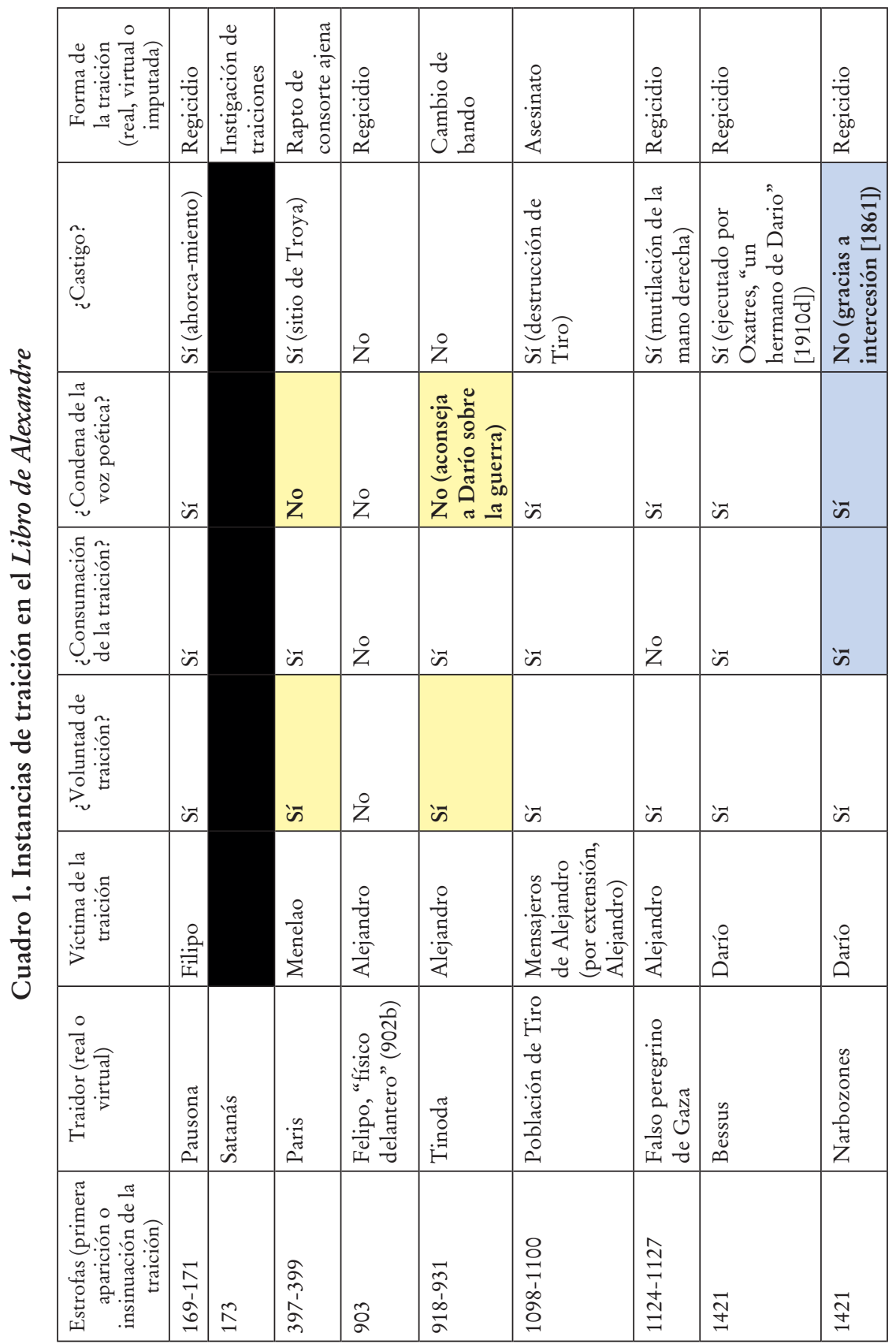


Ruiz • Figura y traición en el Libro de Alexandre 783

\begin{tabular}{|c|c|c|c|c|c|c|c|c|}
\hline 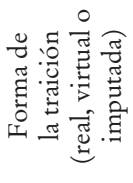 & 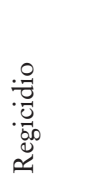 & 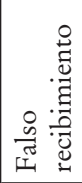 & 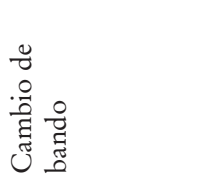 & 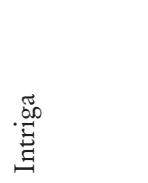 & & $\frac{\stackrel{\pi}{\Xi}}{\stackrel{\Xi}{\Xi}}$ & 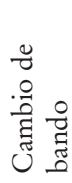 & 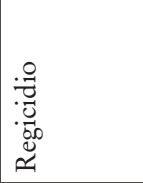 \\
\hline 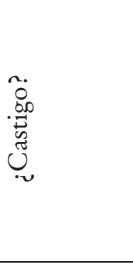 & 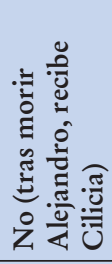 & $\stackrel{\circ}{Z}$ & Z & 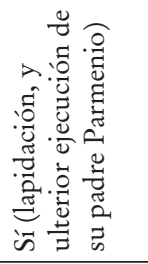 & & 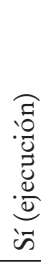 & 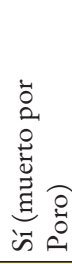 & 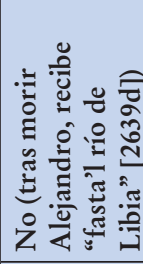 \\
\hline 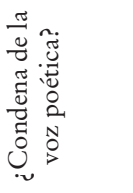 & is & $\stackrel{\circ}{Z}$ & 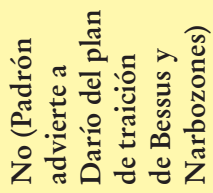 & 莺 & in & $\stackrel{\circ}{Z}$ & $\stackrel{\circ}{Z}$ & in \\
\hline 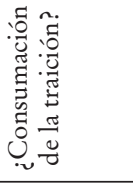 & is & $\stackrel{\circ}{Z}$ & in & $\stackrel{\circ}{Z}$ & & $\stackrel{\circ}{Z}$ & is & is \\
\hline 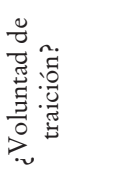 & in & $\stackrel{\circ}{Z}$ & in & 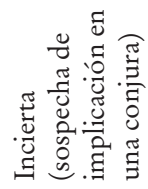 & & $\stackrel{\circ}{Z}$ & in & in \\
\hline 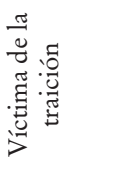 & 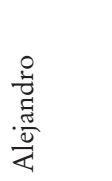 & 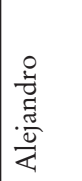 & 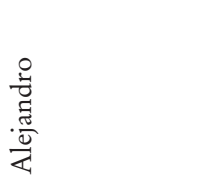 & 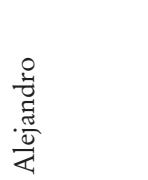 & 总 & $\frac{\stackrel{0}{0}}{\frac{0}{0}}$ & Oั & 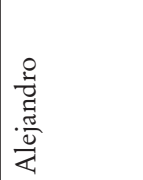 \\
\hline 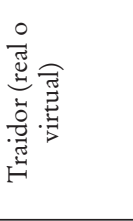 & 志 & 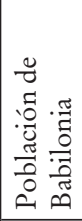 & 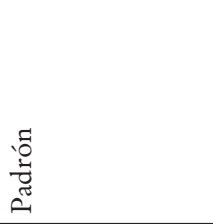 & $\frac{\underset{\Xi}{\tilde{O}}}{\stackrel{0}{0}}$ & 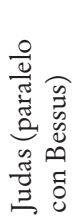 & 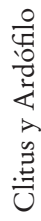 & 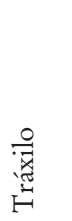 & $\frac{\tilde{\Xi}}{0}$ \\
\hline 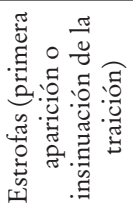 & 官 & $\stackrel{n}{\tilde{n}}$ & $\underset{\sigma}{\sigma}$ & $\begin{array}{l}\hat{\circ} \\
\frac{1}{1} \\
\stackrel{2}{\circ}\end{array}$ & $\vec{\sigma}$ & 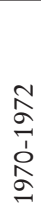 & $\begin{array}{l}\bar{\delta} \\
\text { ते } \\
\text { ò } \\
\text { o }\end{array}$ & $\stackrel{\vec{n}}{\stackrel{n}{2}}$ \\
\hline
\end{tabular}


No he considerado en el cuadro las sediciones colectivas, entre las cuales se encuentran, por ejemplo, la de Armenia (160), Atenas (211) y Tebas (216), con las que Alejandro lidia ejemplarmente. Se advertirá que no todos los casos de traición son efectivos. Más de uno no llega a consumarse, como el intento de asesinato de Alejandro por parte de un hombre disfrazado de peregrino durante la toma de Gaza, al que el poeta exorna con un atributo diabólico emparentado con la silueta de Satanás como instigador de la traición:

Vino en este comedio en guis' de peregrino Avienlo los de dentro ¡oviera ad Alexandre, un omne endiablado, todo muy demudado. asmo que embïado: si por pocas, matado! (1124)

Distingo entre traición real, virtual o imputada con el fin de visibilizar el hecho de que no es siempre la traición materia de condena moral ni material. He resaltado dos tipos de situaciones. El primero (sombreado amarillo) corresponde a aquellos casos en que la voz poética no sanciona negativamente la voluntad de traicionar. Ocurre con Paris, Tinoda, Padrón y Tráxilo. El caso de Paris es especial dado que está inserto en la larga digresión troyana, de la que es responsable el rey macedonio. Por motivos estructurales, entonces, es lógico que no será aquella quien condene moralmente el rapto de Helena; bastará para ello el propio Menelao:

¡Parientes e amigos, de tamaño quebranto, ¡Vayámosnos vengar Respusiéronli todos: por el Nuestro Señor, que vos prenda dolor! del falso träidor!” “¡Müy de buen amor!” (402)

La situación de Tinoda, Padrón y Tráxilo es parecida. Los tres han desertado de sus bandos respectivos. Han traicionado sus lealtades originales. Tinoda y Padrón son griegos que, por razones que el poeta no hace explícitas, han pasado a servir a Darío. Sobre Tinoda, escribe el poeta: 
Otro un alto prínçipe con el rey Alexandre con aquellos que eran passose pora Dario, de los reyes de Greçia ovo desabenençia: de su atenençïa mas non por su fallençia. (918)

No más clara es la presentación de Padrón:

Un prínçip' de los griegos, omne muy venturoso -Padrón era su nombre, al que dé Dios buen poso-, entendió el consejo malo e peligroso.

Dixo: “'Señor, tú me val’, santo e poderoso!”. (1686)

Tráxilo, por su parte, a quien el poeta llama hermano de Poro' ${ }^{9}$ lo abandona para servir a Alejandro. Su destino, como los de Tinoda y Padrón, tampoco merecen condena moral. Sí es, en cambio, muerto por Poro, luego de que el rey indio fuera prevenido por él contra guerrear inútilmente:

Fue Poro contra Tráxilo sañoso e irado, ca, porque lo dexava, era so despagado.

Remetiol'un benablo que le avié fincado:

¡echolo muerto frío sin alma en el prado! (2091)

También he resaltado (sombreado celeste) los casos en que, contando con la condena de la voz poética y la consumación de la traición, la traición queda sin castigo. El primero de los tres casos es el de Narbozones, a quien Alejandro perdona gracias a la intervención de un noble:

Avié ý un ric'omne ovo con sus falagos que non devié naçer;

al rëy a vençer:

\footnotetext{
9 Anota Casas Rigall que "Taxiles, rey del territorio entre los ríos Indo e Hisdaspes, no es hermano de Poro" (2014: 602), debiéndose la atribución de parentesco a una "mala inteligencia” con relación a la lectura del Alexandreis.
} 
cuemo el fierro el fuego, fízol'amolleçer; ¡ovo por él Narbózones de muerte a estorçer! (1861)

Antípater y Jobas quedarán también sin castigo. Tras la muerte de Alejandro, el primero recibe el gobierno de Cilicia. De Jobas dice Alejandro en su testamento: “A Jobas e Cassánder, fasta'l río de Libia” (2639d), es decir, hasta el Nilo.

¿Qué concluir de estas irregularidades? Retorno al concepto de figura y a los problemas derivados de él para la interpretación del poema. Vuelvo a la necesidad de extender las posibilidades de la lectura figural al ámbito de lo que se resiste a ser leído en el plano de lo literal y lo histórico. La evaluación de la traición como materia de interpretación figural conduce, primero, a reconocer que su tratamiento moral en el Alexandre es cuando menos ambiguo. Algunas veces no merece la condena enfática de la voz poética, sino que se inserta en un contexto bélico que lenifica aquello que tiene de reprobable. Otras veces su ejecutor se libra del castigo de un modo inadmisible para el diagrama moral que con ligereza podría adjudicarse al poema. Antes que suponer que estas divergencias en el tratamiento de la traición son producto inevitable de la longitud del texto o de la complejidad de la materia poetizada, prefiero argumentar que corresponden a un diseño figural, es decir, a un diseño construido sobre la base de perfeccionamientos recíprocos y tensiones prospectivas.

Así como, de acuerdo con la interpretación agustiniana, Moisés es figura de Cristo, siendo que el último perfecciona los atributos histórico-teológicos del primero (Auerbach 1998: 80), los diferentes episodios de traición en el Libro de Alexandre configuran una cadena de perfeccionamiento progresivo que inicia con el modo más imperfecto de traición y culmina con aquel que optimiza sus rasgos. Estos últimos, en el Alexandre, se definen por las diferencias entre cada episodio: la efectiva consumación del acto; la impunidad; la deseada condena de la voz poética, que le da espesor transgresivo al evento; y la altura (en el sentido aristotélico de la Poética) de la víctima. Los dos extremos posibles de la traición, según tales 
coordenadas, corresponden a la traición de Pausona y a la traición conjunta de Antípater y Jobas. La de Pausona es figura de la de Antípater y Jobas no solo en virtud del presagio efectivo, sino porque el logro de la impunidad (incluso del premio del testamento) remite a un género de perfeccionamiento del que los diversos episodios intermedios de traición constituyen tentativas o logros progresivos. En el asesinato alevoso de los mensajeros que Alejandro envía a Tiro, por ejemplo, la víctima directa no es el rey macedonio. En la traición de Tráxilo, el gesto traicionero no logra la altura criminal del regicidio; antes bien, Tráxilo busca evitar la muerte de Poro, siendo el cambio de bando y el estado "sañoso e irado" del rey indio lo que determina su muerte. Semejantes deficiencias en la conquista de la veritas anunciada por la traición introductoria de Pausona pueden advertirse en los demás casos detallados en el cuadro 1.

Véase, puesto que creo que ejemplifica adecuadamente mi argumento sobre la imperfección de los actos de traición, lo referido entre las estrofas 1098 y 1100, es decir, el asesinato de los mensajeros enviados por Alejandro a la ciudad fenicia de Tiro. Tras la toma de Damasco y de Sidón, Alejandro se propone la toma por las armas de Tiro luego de que la ciudad se negase a una rendición pacífica. El asedio tiene lugar, pero una tregua lo interrumpe, de manera que Alejandro envía mensajeros para negociar la paz. El poeta conjuga en una sola estrofa los elementos necesarios para calibrar la dimensión de la traición:

Ivan los mandaderos

ovieron los de Tiro

Por sus grieves pecados

¡mataron a los omnes por la paz assentar;

träiçión a asmar.

ovieron a çegar:

que los querién salvar! (1099)

Tiene lugar una condena explícita de la traición, que llega a consumarse, así como su castigo en la toma violenta de Tiro. Algunas estrofas más adelante, el poeta se permite una condena general de los traidores con una intensidad que, curiosamente, difí- 
cilmente aparece en aquellas instancias donde el objeto material e inmediato de la traición es una figura regia:

Siempre devién tal çaga

non devién escapar

ca nin guardan amigos

¡Mala fin prendan ellos prender los träidores;

por nullos fiadores,

nin escusan señores.

e sus atenedores! (1117)

Esta instancia de traición configura un caso excepcional en el poema: el acto se consuma, y su castigo, incorporado a la gesta conquistadora de Alejandro, cuenta con el comentario del poeta. Sin embargo, contrario al precedente inaugural de Pausona (169171), el acto no reorienta el curso de la épica, como sí lo habría hecho lo emprendido por el falso peregrino de Gaza (1124-1127) de haber tenido éxito.

\section{CONSUmaciones de la traición PERFECTA}

No es solo para que la estructura que diviso no termine siendo el producto de un ejercicio estéril que vuelvo al problema de la intelección prospectiva de lo figural. En relación con el Alexandre, Solomon y Temprano establecieron lo prospectivo de la figura según la referida lógica del speculum principis: Alejandro es figura de Fernando III, quien "posee todos los atributos de Alejandro excepto la tacha de su carácter que le llevó a la destrucción” (Solomon y Temprano 17). Complemento a la prefiguración interna observada por Bly y Deyermond ${ }^{10}$, la cadena figural propiciada por el sistema de traiciones problematiza la idea de un adentro y un afuera del texto, sobre el que Solomon y Temprano fundamentan su hipótesis.

\footnotetext{
10 Isabel Uría, advirtiendo la importancia que adquiere la soberbia en el Alexandre en contraste con al Alexandreis de Châtillon, anota, siguiendo a Bly y Deyermond, que la consumación máxima del pecado se engarza a una cadena figural conducente a la derrota del héroe (1996: 522-523). De esa manera, las distintas instancias de soberbia, relativas tanto a Alejandro como a sus antagonistas, articulan la prefiguración de la caída. Como Uría, privilegio aquí un entendimiento intratextual de la figura, con la salvedad de que su consumación última remite al ámbito de la autoría.
} 
Es aquí donde el problema del género del Alexandre retorna como materia de angustia y como corolario de lo expuesto hasta ahora.

$\mathrm{La}$ interrogante actual, la que se deduce de considerar que la forma perfecta de la traición de Antípater y Jobas (cuya cadena causal llega hasta el mismo Dios) ${ }^{11}$ puede ser figura de otra forma de traición, es cómo imaginar esta última. En otras palabras, el problema último reside en cómo imaginar el perfeccionamiento de lo que aparece perfecto según las coordenadas intrínsecas al sistema de traiciones en el poema. La oportunidad de perfeccionamiento hay que buscarla en la víctima de la traición, operando sobre ella el mismo tipo de movimiento que nos llevó a abandonar la búsqueda de lo figural en la dimensión literal del Alexandre. ¿Qué puede ser más terrible que traicionar a un rey del que se es vasallo? Las primeras estrofas dan más de una clave preciosa:

Señores, si quisiéredes querríavos de grado deve, de lo que sabe, si non, podrié en culpa

Mester trayo fermoso: mester es sin pecado, fablar curso rimado a sílavas contadas, mio servicio prender, servir de mio mester: omne largo seer; e en riepto caer.

non es de joglaría; ca es de clerezía por la quaderna vía, que es grant maestría. (1-2)

Raymond S. Willis ha establecido que el asunto de las sílabas contadas ha de interpretarse sinecdóquicamente con relación al saber retórico y poético pertinente al mester clerical (Willis 1957: 217). De manera análoga, quiero ahondar en la gravedad de la obligación que el poeta reconoce sobre su propia persona en el primero de los dos tetrástrofos. La única traición más alta, más crítica y,

\footnotetext{
11 Leemos en la estrofa 2329 del poema que "Pesó al Crïador, que crïó la Natura: / ovo de Alexandre saña e grant rencura. / Dixo: «Este lunático que non cata mesura / yo’l tornaré el gozo todo en amargura!”, con lo que el poeta logra conciliar lo providencial cristiano con el paganismo de la Rueda de la Fortuna.
} 
por ende, más perfecta que podemos imaginar en el marco del texto es aquella que el poeta puede cometer contra su propio oficio. La responsabilidad de "largo seer" en relación con lo que se sabe remite no solo a la hipótesis bernardiana de que el conocimiento no puede venderse puesto que pertenece a Dios (Le Goff 1970: 152), sino, sobre todo, a una relación con el alocutario que sujeta a la voz poética y engendra la posibilidad de ser traidor. Que la traición de Antípater y Jobas, máxima en el plano del enunciado, pueda ser figura de la traición al oficio, al mester, define una tensión de la que la voz, en el plano de la enunciación, no puede librarse. De esa manera se explica que, como ha observado Marina S. Brownlee, la traición no sea en el poema necesariamente el resultado inmediato de una falla moral (Brownlee 1983: 268-269). Se trata de una metódica aproximación a la conciencia de la propia escritura. Con ella, se cierra verdaderamente el círculo explicativo de las digresiones del Alexandre tal como lo enfrentaron Bly y Deyermond: las digresiones - especialmente la troyana- habilitan el esquema figural, pero es finalmente el estremecimiento autocrítico de la voz poética, pensándose a sí misma como virtual consumación de la cadena figural de traiciones, lo que demanda la profusión de digresiones en tanto pago de una deuda.

¿Cómo asimilar esta lección de autoconciencia al marco de las pretensiones del clérigo letrado de principios del siglo XIII que, habiendo o no pasado por la Universidad de Palencia, requería de su mester más de una recompensa terrenal? Arguye Arizaleta que "[l]a composición del Alexandre hubo de ser entendida, por su autor y por los receptores de la obra, como un medio de promoción social”, de manera que "[l]a maestría en el arte de escribir sirvió los propios intereses del autor” (Arizaleta 2008: 81). De esa forma, “a los letrados estarían destinados los contenidos enciclopédicos especializados, y a los menos cultos, los episodios novelescos y épicos” (80). He aquí la consecución de un proyecto que pasa por la gestión pública y no desinteresada de la escritura. Es de notar, no obstante, que la compartimentalización de la lectoría, en atención a una prevista disputa en el ámbito del goce y sus posibilidades, no 
cancela un tipo particular de ansiedad que debió de experimentar el poeta del Alexandre.

Sostiene Simone Pinet que nuestro poeta hubo de ser víctima de la ansiedad originada en el entrecruce de dos órdenes económico-sociales con los cuales se ha de pensar tanto la historia de Alejandro como el propio mester. Por un lado, el sistema de dones, tal como aparece en la épica, y, por otro, "the new system of profit as one especially valuable in the hands (and lips) of those working or dealing with language" (Pinet 61) ${ }^{12}$. Es en esa dimensión que el análisis figural que propongo enriquece la tensión económica relativa al valor de cambio estipulado en y a través del texto. En última instancia, el poema radicaliza las ansiedades del autor como productor, no solo con relación a una esfera palatina capaz de retribuir sus hazañas en materia de estudio y composición. Se trata, sobre todo, de su inscripción en un sistema económico que demanda y exacerba la autoconciencia de quienes tienen al lenguaje como principal objeto transaccional (Pinet 2006: 60-62). Ello explica parcialmente que el Libro de Alexandre instituya caminos de economía narrativa que devienen eficaces más allá del horizonte de producción y consumo en que se articularon originalmente.

\section{DOS CONCLUSIONES: ANSIEDADES AUTORIALES Y MODERNAS REDES INTRATEXTUALES}

Hasta aquí, he buscado apuntalar la productividad de una lectura figural del Libro de Alexandre que aproveche las iteraciones de la traición como eje para repensar la estructura del texto y la aprehensión de sus elementos digresivos. El mapeo de las instancias de traición en el poema revela un arreglo heterogéneo donde la sanción moral nunca es unívoca, como tampoco es estable el éxito de la traición en sí. Tomada como punto de articulación que atra-

12 En "Toward a Political Economy of the Libro de Alexandre", Pinet (2006) demuestra con éxito que "A certain mastery overy money and especially its rhetorical possibilities is thus also the task of the cleric. At a point when such mastery has just been claimed as a cleric's doing, this catch-22 is expressed as uneasiness, discomfort, contradiction" (54). 
viesa el Alexandre y genera correspondencias que la noción de figura contribuye a iluminar, la traición ha de ser leída no solo como motivo o evento de sinuosa recurrencia, sino también y sobre todo como dispositivo de autoconciencia poética. El anónimo autor del Alexandre, mediante la metrificada conciencia de su oficio y la elocuencia respecto a la composición hipertextual que emprende ${ }^{13}$, dispone que las ansiedades de la creación poética se incorporen a las lógicas constitutivas del poema. La traición del propio oficio ${ }^{14}$ : consumación virtual de un sistema figural cuya agudizada autoconciencia no habrá de verse al menos hasta la afirmación del yo escriturario en la obra de Don Juan Manuel.

El examen del Alexandre orientado hacia la elucidación de la figura echa luces sobre opciones contemporáneas que la ficción en español asume frente a los entusiasmos y desilusiones que emanan de los discursos sobre el agotamiento de la novela y de la literatura en general. La tensión entre hacedor y materia, eje del mester representado por el Libro de Alexandre, vuelve de la mano de una estructura de correspondencias que debe mucho a las particularidades de nuestro mundo digitalizado y que sugiere una actualización de la cadena figural. Recuerdo, por ello, una novela reciente. En el 2018, el físico coruñés Agustín Fernández Mallo obtuvo el Premio Biblioteca Breve de Novela que concede anualmente la editorial Seix Barral con la novela Trilogía de la guerra. Como indica el título, la novela tiene tres partes: la primera se ocupa de las aventuras de un escritor español perdido entre Nueva York y Sudamérica; la segunda, de las desventuras del secreto cuarto astronauta de la misión Apollo 11; la tercera, de los vagabundeos

13 Un ejemplo más de la porosa frontera entre auctor y compilator al inicio de la la larga descripción de Asia en la estrofa 281: "Dexemos de las otras: de Asia nós contemos / a lo que començamos, en esso nos tornemos: lo uno que leyemos e lo ál que oyemos, / de las mayores cosas recabdo vos daremos” (el énfasis es mío).

14 Como observó Francisco Rico, no puede entenderse el significado del mester del Alexandre con referencia exclusiva a "una escuela poética en romance" (1985: 148): la traición al oficio, entendida aquí como virtualidad que consuma la figura en los límites de lo puramente textual, compromete la relación con un estatus cuasiestamentario (127-130). 
de la esposa del escritor de la primera parte en la costa normanda. El arreglo formal de la novela se integra a un horizonte de textos narrativos de publicación reciente en España a los que Geneviève Champeau ha conferido el mote de "relatos reticulares" (Champeau 2011: 72-80). El nexo que encuentro entre tales narrativas —en particular, la novela de Fernández Mallo-y el Libro de Alexandre tiene que ver con uno de los rasgos que definen lo reticular: la multiplicación de un conjunto finito de cuasieventos, que no son propiamente motivos ni acontecimientos, sino destellos narrativos o, simplemente, semejanzas que se abren paso por el texto y engendran un mapa de conexiones de ardua decodificación. Hay muchas formas de reconciliarse, en el comentario de una novela de esa índole, con la divisa perezosa de lo posmoderno. Tal vez víctima de un anhelo de continuidades históricas, prefiero tomarla como signo que alerta sobre la validez secular de una estructura - la figural o tipológica- que conjuga el amor de lo diverso y lo semejante.

\section{REFERENCIAS BIBLIOGRÁFICAS}

Agnew, Michael

2000 "La construcción de un modelo exegético en el Libro de Alexandre". La Corónica: A Journal of Medieval Hispanic Languages, Literatures, and Cultures. 29, 2, 159-183.

Arizaleta, Amaia

2000 "Alexandre en su Libro". La Corónica: A Journal of Medieval Hispanic Languages, Literatures, and Cultures. 29, 2, 3-20. https://doi.org/10.1484/J.TROIA.1.100239

Arizaleta, Amaia

2008 "El Libro de Alexandre: El clérigo al servicio del rey". Troianalexandrina. 8, 73-114.

Auerbach, Erich

1998 Figura. Trads., Yolanda García Hernández y Julio A. Pardos. Madrid: Trotta.

BARTHES, Roland

1972 Crítica y verdad. Trad., José Bianco. Buenos Aires: Siglo XXI. 
Berceo, Gonzalo de

1979 El Libro de Alixandre. Ed., Dana Arthur Nelson. Madrid: Gredos.

Bly, P. A. y A. D. Deyermond

1972 "The Use of Figura in the Libro de Alexandre". Journal of Medieval and Renaissance Studies. 2, 2, 151-181.

BORGES, Jorge Luis

1984 “Tres versiones de Judas”. En Obras completas: 1923-1972. Ed., Carlos V. Frías. 14ª edición. Buenos Aires: Emecé, 514-518.

Brownlee, Marina Scordilis

1983 "Pagan and Christian: The Bivalent Hero of El Libro de Alexandre". Kentucky Romance Quarterly. 30, 3, 263-270. https://doi.org/10.1080/03648664.1983.9926390

Cacho Blecua, Juan Manuel

1994 "El saber y el dominio de la Naturaleza en el Libro de Alexandre". En Actas del III Congreso de la Asociación Hispánica de Literatura Medieval (Salamanca, 3 al 6 de octubre de 1989), Tomo 1. Ed., María Isabel Toro Pascua. Salamanca: Biblioteca Española del Siglo XV, 197-207.

Cañas Murillo, Jesús

1995 "Didactismo y composición en el Libro de Alexandre". Anuario de Estudios Filológicos. 18, 65-79.

Casas Rigall, Juan (ed.)

2014 Libro de Alexandre. Madrid: Real Academia Española.

Cervantes, Miguel de.

1997 Don Quijote de la Mancha. Ed., Tom Lathrop. Newark: Juan de la Cuesta.

Champeau, Geneviève

2011 "Narratividad y relato reticular en la novela española actual". En Nuevos derroteros de la narrativa española actual: Veinte años de creación. Eds., Geneviève Champeau, Jean-François Carcelén, Georges Tyras y Fernando Valls. Zaragoza: Prensas Universitarias de Zaragoza, 69-85.

Fernández Mallo, Agustín

2018 Trilogía de la guerra. Barcelona: Seix Barral. 
Le Goff, Jacques

1970 "Church time and merchant time in the Middle Ages". Information (International Social Science Council). 9, 4, 151167. https://doi.org/10.1177/053901847000900411

Michael, Ian

1970 The Treatment of Classical Material in the Libro de Alexandre. Manchester: Manchester University Press.

PINET, Simone

2006 "Toward a Political Economy of the Libro de Alexandre". Diacritics. 36, 3-4, 44-63. https://doi.org/10.1353/dia.0.0008

Rico, Francisco

1985 "La clerecía del mester”. Hispanic Review. 53, 2, 127-150. https://doi.org/10.2307/473318

Riva, Fernando

2018 "Linaje babilónico y soberbia luciferina en el Libro de Alexandre". Bulletin of Hispanic Studies. 95, 10, 1031-1051. https://doi.org/10.3828/bhs.2018.60

Rubio Tovar, Joaquín

2004 La vieja diosa: De la Filología a la posmodernidad. Alcalá de Henares: Centro de Estudios Cervantinos.

Solomon, Michael R. y Juan Carlos Temprano

1982 "Modos de percepción histórica en el Libro de Alexandre". INTI: Revista de literatura hispánica. 15, 2-24.

URíA, Isabel

1996 "La soberbia de Alejandro en el poema castellano y sus implicaciones ideológicas”. Anuario de Estudios Filológicos. 19, 513-528.

VODIČKA, Félix

1989 "La estética de la recepción de las obras literarias". En Estética de la recepción. Ed., Rainer Warning. Madrid: Visor Libros, 55-62.

WiLlis, Raymond S.

1957 " «Mester de clerecía.» A Definition of the Libro de Alexandre". Romance Philology. 10, 3, 212-224. 